\title{
Book review: Violence and Political Theory by Elizabeth Frazer and Kimberly Hutchings, Polity Press, 2020, 229 pages. ISBN-13:978- 1-5095-3671-9
}

\author{
Elina Penttinen \\ University of Helsinki, FI \\ elina.penttinen@helsinki.fi
}

Keywords: political philosophy; violence; storming of the Capitol

On 6 January 2021, a mob of right-wing extremists stormed the Capitol building in Washington, DC, to challenge the final certification of the electoral victory of President-elect Joe Biden. ${ }^{1}$ Inspired by the morning speech of then President Donald Trump, the supporters made their way to the Capitol building to 'stop the steal' ${ }^{2}$ and to 'take back their country'. During the attempted insurrection, five people were killed, including a police officer, and the historical premises of the Capitol were seriously damaged. Pipe bombs and other weapons were also found nearby, demonstrating a premeditated potential use of deadly force.

In this context of this political uprising and right-wing populist attempts to overturn the election results, it is truly interesting to read 'Violence and Political Theory', written by Elisabeth Frazer and Kimberly Hutchings. The book examines in detail the conceptual relationships between politics and violence, and how different political theorists attempt to settle and resolve these ties. This discussion paves the way for the political theory of violence that the authors propose at the end of the book, based on an analysis of the practice and meaning of violence. Moreover, the authors show that it is common to aestheticise violence in political theory or to incorporate it into some other category 'such as resistance, revolution, justice, punishment, self-defence, sovereignty, the gendered martial virtues and vices of courage or cowardice, or the aesthetic categories of tragedy and beauty' (Frazer and Hutchings 2020, 176). Violence, as Fraser and Hutchings argue, 'becomes more palatable when it takes the form of rectifying egregious wrongs and is provoked by a sense of immediate injustice in the innocent oppressed' (Fraser and Hutchings 2020, 177). Indirectly, the book also shows how these strategies of justification materialise and come alive in events such as the storming of the Capitol, as the Trump supporters perhaps believed that they were justified in their actions for the purpose of 'taking back the country'.

\footnotetext{
${ }^{1}$ Visual Journalism Team, 'Capitol Riots: A Visual Guide to the Storming of Congress,' BBC News, January 7, 2021, accessed May 7, 2021, https://www.bbc.com/news/world-us-canada-55575260.

2 Sam Cabral, 'Capitol Riots: Did Trump's Words at Rally Incite Violence?,' February 14, 2021, accessed May 7, 2021, https://www.bbc.com/news/world-us-canada-55640437.
} 
The central theme in this book is, however, challenging the tacit assumptions around violence and its connection to politics. It shows how violence in political theory is often taken for granted and simply regarded as part of human nature. Throughout the book, the authors show that when the use of metaphors to describe violence or the minimalisation of violence by including it in another category is removed, it becomes increasingly difficult to justify the use of violence, and furthermore that any attempt to moralise or justify the use of violence ends up reproducing hierarchic categories of gender, race and class. Therefore, the main emphasis in the book is to take a look at violence directly, and indeed build a political theory of violence that begins from the acknowledgement of the practice of violence, instead of the ends it serves.

The book includes analyses of 25 different political theorists, from periods ranging from the fifteenth century to the current day, covering each century's prevalent political thinkers. The theorists presented in the book range from early to modern classics, including thinkers such as Macchiavelli, Locke, Marx and Engels, Beavoir, Arendt, Ghandi, Fanon, Foucault, Derrida to Elshtain, Ruddick and ending with Elaine Scarry. Each theorist's arguments are reviewed specifically in terms of how they deal with the question of violence and its relation to politics. This results in an interesting dialogue between the thinkers, going beyond their traditional representations familiar from textbooks on political theory, which usually only categorise them in chronological order. Instead, in this book, the theorists are divided into categories such as statist, revolutionary, conservative and critical political thinkers, and the book then proceeds by analysing the arguments, meanings and conceptualisations of violence by these different thinkers in individual chapters.

This, in a way, is one of the main achievements of the book. By dissecting the arguments of such a wide range of thinkers across a broad time span, the books shows how difficult it is to theorise violence without resorting to reframing it through another category, and thus distancing the discussion of political violence from the real consequences, destruction and trauma that it entails. In political theory, as long as the debate is on state domination, anarchy, revolution or the protection of vulnerable groups, violence is certainly always present and acknowledged, yet it is also dealt with in a manner that removes it from the actual practices and experiences of violence. Indeed, as already mentioned, violence is usually either subsumed into some other category, dealt with in between the lines, or as a side note, rather than as the main part of a political theory. Frazer and Hutchings show the ambivalence of justifications for the use of violence by juxtaposing the arguments and ideas between the different thinkers. This strategy works well in terms of teasing out how difficult it is to address the question of violence in political theory without the use of metaphors or a level of abstraction. The authors show how even though the background and objectives of the theorists are different, they have difficulties in resolving or settling the question of political violence without reiterating hierarchical categories of gender, race and class, or resorting to the normalisation and aestheticisation of violence. In so doing, the book reveals how deeply violence is embedded and normalised not only in political theory but also more widely in culture and society.

In moving forward with the political theory of violence, the authors argue that violence should never be an acceptable part of politics. This is because the outcomes of violence are not only disastrous but also unpredictable and complex. The authors emphasise, following Arendt, that the only predictable outcome of violence is more violence. To fight violence with violence, as the authors put it, is only to endorse it. Therefore, the authors put forth a political theoretical approach to violence that questions the meaning, explanation and justification of political violence (p.187), and which tackles violence directly instead of reducing or hiding it in other categories. The book challenges the readers to rethink the common sense understanding of violence as simply a part of life, or a part of human nature, and seeks to create a new conceptualisation that denounces violence as an integral or justifiable means of politics. 
For this purpose, the authors bring in the work of Elaine Scarry, whose background is in literary and cultural theory rather than in political philosophy. Scarry's work begins by approaching the question of violence from a different angle than is usually done in political theory, as she theorises violence as politics. For Scarry, the experienced sensation of pain and the physical wounding of bodies are central, instead of the purpose, ends and means of the politics that the violence is intended to serve. From this perspective, the authors shine a light on the problematic way in which the pain and suffering linked with violence is left untouched and undertheorised in political philosophy. Scarry also emphasises that the outcomes of violence may not be long lasting and thus not effective as such. Societies and communities are able to recover, heal and transform even after the most atrocious violent conflicts. Therefore, even though it may seem that violence is the way to dominate, control and conquer, in practice these outcomes are never final or long lasting.

It is interesting and quite telling of the canon of political theory that a theorist from cultural studies is referred to here as a someone who comes closest to a direct assessment of violence in the context of political theory. Thus, this book could also be read as a critical assessment of the level of analysis by which violence is addressed in political theory, and how it is often normalised in fields such as International Relations, even including more critical sub-fields. The book is thus somewhat positioned as a critical perspective on the norm of distancing, or rather dissociation, from the real pain and suffering that is inextricably linked to violence. Indeed, the difference in Scarry's background could perhaps have been elaborated on further, as it reveals something interesting about how the distancing and aestheticisation of violence are related to the level of analysis in specific disciplines in politics and International Relations. However, it could also be noted that the approach to violence that aims to deal with it directly by acknowledging the experiences and practices of violence has been growing in feminist International Relations and feminist peace research scholarship. For example, Christine Sylvester's work on touching war was aimed at theorising war directly through the experience of violence (Sylvester 2011, 2013), and also challenged the way in which war is addressed indirectly or through another category of power politics or war strategies, and how the effects of war were thus removed from these discussions. Similar discussions continue in feminist peace research (see e.g. Väyrynen et al. 2021), which engages in critical discussion on lived experiences, gender and agency in the context of political violence and the interconnectedness of direct, indirect and structural violence. These lines of scholarship are similarly based on a multidisciplinary approach and theoretical stance that is not limited to the political philosophers critically assessed in Violence and Political Theory.

However, something also has to be said of the careful and detailed analysis of the different strategies of justification of violence that Frazer and Hutchings offer in this book. Frazer and Hutchings categorise these different strategies as follows: conceptualising violence as a tool for something, violence as a given of politics, violence justified in terms of the intention for which it is used, as a matter of self-defence, protecting the weak, or by categorising it in terms of good and bad violence. Albeit that the authors show that all of these positions are untenable when considered from the perspective of violence as politics, and taking into account the impossibility of determining the outcomes of violence, for the reader it becomes clear that the arguments presented in the book still resonate with the arguments that are used today to justify the use of violence.

This brings us back to the discussion of the January 6th riots at the Capitol in Washington, DC, mentioned in the beginning of this review. The Trump supporters found out the hard way that the outcome of political violence is unpredictable, and perhaps short lived. Instead of stopping the certification of the election as they had hoped, the storming of the Capitol resulted in over 400 arrests $^{3}$ and Trump facing a second impeachment trial and being

${ }^{3}$ Clare Hymes, Cassidy McDonald, and Eleanor Watson, "What We Know About the "Unprecedented" U.S. Capitol Riot Arrests,' CBCNews, May 4, 2021, accessed May 7, 2021, https://www.cbsnews.com/news/capitol-riotarrests-2021-05-04/. 
banned from social media, and also not offering any pardons to his supporters. The events at the Capitol also showed how the justificatory strategies presented in the book Violence and Political Theory can be, and still are, used to manipulate crowds and indeed incite more violence.

For this reason, the book is an important resource for scholars teaching courses on political theory, politics and violence, and associated critical approaches, as it enables the identification of the different means by which violence is justified, normalised and mobilised for political purposes. As the book presents the arguments of 25 different theorists in less than 190 pages, students unfamiliar with the work of the theorists presented in this book would probably need extra reading to make the book more accessible. However, for scholars researching violence from a multidisciplinary background, the textbook itself is a concise set of materials and very helpful in inspiring discussion about how violence is understood and theorised in the context of political philosophy.

In closing, the authors call for a political theory that would neither aestheticise violence nor take it for granted but instead would imagine politics in which the justifiability of violence is denounced. What this political imagination would be is not answered in this book but is left for the reader to expand on. I will certainly be on the lookout for what these authors produce next, and how they further develop the political theory of violence outlined in this book.

\section{Competing Interests}

The author has no competing interests to declare.

\section{References}

Frazer, Elizabeth, and Kimberly Hutchings. 2020. Violence and Political Theory. Cambridge, UK: Polity Press.

Sylvester, Christine. (ed.) 2011. Experiencing War. London, UK: Routledge. DOI: https://doi. org/10.4324/9780203839997

Sylvester, Christine. 2013. War as Experience: Contributions from International Relations and Feminist Analysis. London, UK: Routledge. DOI: https://doi.org/10.4324/9780203100943

Väyrynen, Tarja, Swati Parashar, Élise Féron, and Catia Cecilia Confortini. (eds.) 2021. Routledge Handbook of Feminist Peace Research. London, UK: Routledge.

How to cite this article: Penttinen, Elina. 2021. "Book review: Violence and Political Theory by Elizabeth Frazer and Kimberly Hutchings, Polity Press, 2020, 229 pages. ISBN-13:978-1-50953671-9." Redescriptions: Political Thought, Conceptual History and Feminist Theory 24(1), 85-88. DOI: https://doi.org/10.33134/rds.350

\section{Submitted: 20 May $2021 \quad$ Accepted: 01 June $2021 \quad$ Published: 22 July 2021}

Copyright: (c) 2021 The Author(s). This is an open-access article distributed under the terms of the Creative Commons Attribution 4.0 International License (CC-BY 4.0), which permits unrestricted use, distribution, and reproduction in any medium, provided the original author and source are credited. See http://creativecommons.org/licenses/by/4.0/. 